\title{
Management of the Care Homes for Older Adults During COVID-19 Pandemic
}

\author{
Daniel Pavlovski \\ $\mathrm{PhD}$, Associate Professor at University "Mother Teresa”, Skopje, \\ Republic of North Macedonia \\ Ognen Aleksoski \\ MS, PhD candidate at University "Goce Delcev", Shtip, \\ Republic of North Macedonia
}

\section{Abstract}

The older adults are one of the categories of the population that is particularly vulnerable to the COVID-19 virus, both in terms of infection rate and mortality rate. Therefore, in the age of a global pandemic, is particularly complex the management of the care homes, which can become hotspots of the virus. Managing of the care homes for older adults during COVID-19 pandemic is facing with number of challenges, the most important are: 1) lack of protocols and guidelines for care homes with clear and applicable measures and activities; 2) lack of measures to deal with the economic consequences of the crisis. However, despite these shortcomings, the managers of care homes in the Republic of North Macedonia, until the end of April, successfully dealt with the pandemic and did not allow the spread of the virus among care homes residents and employees. The data shows that in 18 from total 30 care homes, have only five registered cases positive for COVID-19 ( 2 care homes residents and 3 employees), which is $0.33 \%$ of the total registered cases in the country. This shows that the management and employees have taken appropriate measures and activities in order to protect against the spread of the virus in the care homes in the Republic of North Macedonia.

Keywords: older adults, management, care homes and COVID-19 


\section{Introduction}

In December 2019, in the city of Wuhan, in the province of Hubei in the People's Republic of China, a new coronavirus appeared and began to spread in a short time in other provinces of the People's Republic of China. Coronaviruses are a large family of viruses that can cause disease in humans and animals. Several coronaviruses are known, that cause respiratory infection to humans, such as MERS and SARS, while the most recently discovered coronavirus is COVID-19.

COVID-19 is an acute respiratory disease caused by a novel human coronavirus (SARS-CoV-2, called COVID-19 virus), which causes higher mortality in people aged $\geq 60$ years and in people with underlying medical conditions such as cardiovascular disease, chronic respiratory disease, diabetes and cancer (World Health Organization, 2020).

On March 11, 2020, the World Health Organization declared a pandemic of the new coronavirus COVID-19, due to the fact that it is a new type of coronavirus and it has spread to several continents. Regarding this, the World Health Organization sent a strong and clear message to all countries in the world that the situation with COVID19 is extremely serious and that every country must start preparing to deal with this crisis.

The Government of the Republic of North Macedonia on February 25 at its eleventh session adopted the first official document for prevention of the spread of coronavirus COVID-19, followed by other decisions, conclusions, measures and recommendations.

On March 13, 2020, it was adopted decision on the existence of a crisis situation on part of the territory of the Republic of North Macedonia, in order to prevent the spread of coronavirus COVID-19 (Official Gazette of the Republic of North Macedonia no. 63/2020).

Due to the further deterioration of the situation with the virus, on March 18, 2020, a Decision was adopted for the existence of a state of emergency on the entire territory of the Republic of North Macedonia (Official Gazette of the Republic of North Macedonia no. 68/20120).

On March 21, a Decision was adopted which: 1. Prohibits the movement of the population on the territory of the Republic of North Macedonia, in the period from 21:00 to 6:00 the next day; 2 . The movement of vehicles from public transport on the territory of the Republic of North Macedonia is prohibited, in the time period from 21:00 to 6:00 the next day (Official Gazette of the Republic of North Macedonia no. $72 / 20120)$. 
Regarding the situation with COVID -19, the data of the Institute of Public Health of the Republic of North Macedonia shows that the first case was confirmed on 26.02.2020. At the end of February (29.02.2020) in the Republic of North Macedonia the total number of confirmed cases of COVID-19 is 1 and there are no deaths, on 31.03.2020 the total number of confirmed cases is 354 and there are a total of 2 dead persons, while on 30.04.2020 the number of confirmed cases is 1494 and the number of COVID-19 deaths is 81 (Institute for Public Health of the Republic of North Macedonia, 2020).

Statistical data on the number of confirmed cases of COVID-19 in the Republic of North Macedonia show that at the end of March 2020 the largest number of patients, that is $22.3 \%$, are over the age of 60 (Institute of Public Health, 2020).

The number of confirmed cases in the world on 29.02.202 in total is 85,403 and 2,924 COVID-19 deaths. As of March 31, 2020, the number of confirmed cases is 750,890 and 36,405 dead, while on 30.04.2020 the number of confirmed cases is 3,090,445 and 217,796 dead (World health Organization, 2020).

The COVID-19 pandemic has affected older adults disproportionately, especially those living in long-term care facilities. In many countries, evidence shows that more than $40 \%$ of COVID-19 related deaths have been linked to long-term care facilities, with figures being as high as $80 \%$ in some high-income countries. Furthermore, in long-term care facilities, the case fatality for residents with COVID-19 may be higher than in the population of the same age living outside long-term care facilities (World Health Organization, 2020).

Care home residents are particularly vulnerable to COVID-19 as a consequence of their complex medical problems and advanced frailty. The outbreaks in care homes have proven to be devastating for the care home residents (British Geriatric Society, 2020).

In such conditions, the management of elderly care homes is particularly complex and the managers of these institutions face numerous challenges on a daily basis. One of the key tasks of managers is to take measures and activities in order to prevent the virus from entering the institution, prevent the spread of the virus in the institution and prevent the spread of virus outside the institution (if it has already entered the institution). However, at the same time, all other activities should be managed, such as managing the revenues and expenditures and managing the services, which are also affected by the new situation. 


\section{Methodology}

In order to collect relevant information for the research, a questionnaire was created which refers to the management of the care homes during COVID-19 pandemic. The questionnaire consists of five parts: 1) general information 2) situation with cases positive for COVID-19 3) management of COVID-19 protection measures 4) service management and 5) revenue and expenditure management. With the questionnaire are collected data for the months of February, March and April. The data for the month of February are considered as a control data taking into account that at the end of this month there was only one confirmed case of COVID-19 in Republic of North Macedonia and no pandemic had been declared yet, nor were undertaken serious restrictive measures. The prepared questionnaire was sent by email to the managers of the care homes and they were asked to be completed and returned by e-mail. Questionnaire was sent to all accredited care homes in the Republic of North Macedonia, 5 public and 30 privates, from which answers were received from 4 public (80\%) and 14 privates (46.6\%) care homes, that is 18 $(51,4 \%)$ of the total number of the care homes.

The data collection with the questionnaire was realized in the period from 20 to 30 May 2020.

After the completed questionnaires were received from care homes, technical and logical control of the answers was made, the open questions were closed and categories for data processing were made. Questionnaire data were entered into SPSS data processing software and the processed data are displayed in absolute amounts and percentages.

\section{Ethical considerations}

The information on the number of accredited care homes for older adults in the Republic of North Macedonia and their email addresses are obtained from the Register of elderly care homes which is published on the official website of the Ministry of Labor and Social Policy. Through e-mail, the managers of the care homes received an explanation for the purpose of the research and information that the questionnaire should be completed by the manager of the institution. Respondents also signed a statement agreeing that the data can be used for scientific purposes.

\section{Results}

\section{General information's}

In terms of the gender of the managers, the data shows that $50 \%$ of public care homes managers are female and $50 \%$ male, while in the private care homes $65 \%$ are female and $35 \%$ are male, in total $11(61.1 \%)$ of managers are female and 7 (38.9\%) are male. 
The data on the nationality of the managers shows that in the public and private care homes from which data were obtained, all the managers are of Macedonian nationality.

When it comes to the level of education, the data shows that the managers of all public care homes have higher education, while in private care homes most of them, i.e. 50\% of the managers ( 7 managers) have secondary education, $42.9 \%$ (6 managers) have higher education and only $7.1 \%$ (one manager) have a master's degree. The data shows that from total number of managers (18), 10 (55.5\%) of them have higher education, $1(5.6 \%)$ have a master's degree, while 7 managers $(38.9 \%)$ have secondary education.

In terms of number of employees in the care homes, the data shows that in the months February and March, in the surveyed 4 public care homes, the number of employees is the same and totals 138 employees, while in April it was reduced to 136. The reduction is due to the retirement of one employee from one institution, and which job place has not yet been filled with a new employee, and one employee from another institution who voluntarily resigned for fear of the virus. As for the private care homes, the data shows that in 14 private institutions in February there are 260 employees, in March the number of employees is 257, while in April the number of employees is 265. In March there are reduction due to the fact that three employees voluntarily for fear of virus, resigned from the job, while the increase in April was due to the fact that some care homes have employed additional staff. The total number of employees in the care homes that are part of the survey (public and private) is 398 in February, 395 in March and 401 in April.

Regarding the number of employees, two of the public care homes, or half of the respondents stated that they have a shortage of staff, while only one of the private institutions since the beginning of the crisis has a shortage of staff.

Data on the number of residents in public care homes shows that in February in 4 public institutions has a total of 493 residents in March the number of residents is reduced to 473, while in the month April the number of residents is 449. The decrease in the number of residents is a result of the fact that public care homes do not accept new residents as a preventive measure. Regarding the number of residents in the private care homes, the data show that in February the number of residents is 479, in March the number of residents is 487, while in April the number of residents is 498 . The total number of residents in public and private care homes in February is 972, in March 960 and in April 947. 


\section{Situation with positive cases for COVID-19}

By the end of April in the public care homes there are 2 residents positive for COVID19. While in none of the 14 surveyed private care homes there isn't persons who are tested positive for COVID-19. From these data it can be concluded that in the surveyed 18 (public and private) care homes there are only two residents who are positive for COVID-19. Also, the data shows that neither in the public nor in the private care homes in the mentioned period no care home resident died in whom the presence of the virus was detected.

However, in two of the public care homes there were 5 residents ( 3 from one elderly care home and 2 from another) who were in isolation which was realized in the rooms of the residents. Meanwhile, in one of the surveyed private care homes, 11 care homes residents were in isolation for a period of two weeks. From these data it can be concluded that out of the total number of care homes residents, which are part of the research, a total of 16 care homes residents were in isolation. However, after the end of the isolation period, these care homes residents were tested negative for COVID19.

Regarding the employees, the data shows that by 30.04 .2020 in one public care home one employee was tested positive and in another care home two employees were tested positive for the virus. While no employee in private care homes has tested positive for COVID-19. Which shows that by the stated date, out of the total number of employees in the public and private care homes covered by the research, only 3 staff members have been tested positive for the COVID-19 virus.

Regarding the isolation process, the data shows that in one of the public care home 8 employees and 14 employees in another, as well as 1 of the employees from a private care home were in self-isolation in their homes in a period of two weeks. Which means that in total 23 of employees in public and private care homes were in isolation. However, the tests performed after the end of the self-isolation period did not reveal the presence of the virus in any of the mentioned persons and they did not develop symptoms of the disease.

\section{Management of the COVID-19 protection activities}

Regarding the question whether you received appropriate procedures, protocols and/or instructions for work during COVID-19 pandemic from the competent state institutions, the managers of the care homes answered that they received the general recommendations created by the Ministry of Health. In the answers of the managers is emphasized that until the moment of conducting the research, they have not received protocols that have been created (developed) for the care homes and adapted to their needs.

When it comes to implementation of the general guidelines received by the Ministry of Health for work during COVID-19 pandemic, all care homes stated that they have no problems in their application. 
In order to effectively deal with the consequences of the pandemic with the COVID19 virus, the managers and employees of the care homes have undertaken the following activities:

- Prohibition of visits in the care homes;

- Measurement of the temperature of the employees upon entering in the care

- home;

- Admission of new residents only with negative test for COVID-19 (private care

- homes);

- Prohibited admission of new residents in the public care homes;

- Use of personal protective equipment by all employees;

- Practicing physical distance in all situations when is possible;

- In order to practice physical distance, food is distributed in the rooms of the care

- homes residents;

- Maintaining a high level of personal hygiene by employees and residents;

- Regular use of disinfectants;

- Conduct self-isolation of employees who have had contact with a positive or suspicious

- for COVID-19;

- Implementation of isolation of residents showing COVID-19-like

- Symptoms;

- Increased usage of fruits and vegetables;

- Usage of vitamin supplements by care homes residents.

\section{Activities Management}

All care homes, public and private, have adjusted their daily activities to the new situation. This means that group activities in which it is not possible to maintain physical distance are stopped. On the other hand, group activities are practiced only in the open space, respecting the safe distance between residents, some of the group activities are conducted online and the number of individual activities is increased.

Regarding the realization of the visits of the care homes residents by their families and relatives from 26.02.2020, it was introduced a ban for the realization of visits in the care homes. All public and private institutions stated that they have no problems in enforcing this ban and have understanding from care homes residents and their families, who are aware that it is in the best interest of the older adults. 
Having in mind that in the Republic of North Macedonia from 18.03.2020 a state of emergency was declared and in different periods there were restrictions on the movement of the population (curfew) some of the care homes stated that they were forced to introduce changes in the way of organizing the working hours. The data shows that $2(50 \%)$ of the public and $8(51.7 \%)$ of the private care homes, i.e. a total of $10(66.6 \%)$ have introduced changes in the working hours of their employees. Changes and problems in the organization of working hours that face these institutions, further is compounded because of restrictions in the organization of public transport in the cities, so they are forced at their own expense to organize transport of their employees, which affects the increasing costs of the care homes, but also in terms of logistics aspects related to the organization and implementation of transport.

Regarding the communication of the care homes staff with the care homes residents, the data shows that at the beginning of the pandemic, in all institutions the residents had a number of questions related to the virus and the measures taken against it. Therefore, the staff in the care homes made additional efforts in order to fully, timely and properly inform the care residents.

Regarding the communication of the care homes residents with their families, given that visits are prohibited, the institutions have made additional efforts to enable the older adults to be able to communicate with their loved ones. Whether the care homes residents have their own mobile phone or not, all the care homes allow their residents to contact their loved ones through the official telephones of the institution and with the help and assistance of the staff who help the residents in using the technology for telephone and video calls. From the obtained data it can be concluded that in all 4 public and 14 private care homes, the communication of the older adults with their families is realized through mobile phones and video calls.

Also, according to the obtained data, the communication of the family members of the care homes residents with the employees in the care homes takes place by phone and without any problems.

In order to improve the functioning of the care homes during COVID-19 pandemic the data shows that the managers of all care homes, public and private, on a daily basis practiced intensive two-way communication with their employees in order to timely and efficiently transmit information and instructions.

Regarding the communication between the care homes and the official public institutions, the data shows that all managers of the public care homes evaluated the communication as good, while $10(71.4 \%)$ of the managers of the private care homes evaluated it as bad and only 28.6\% (4) consider it good. In total 8 (44.4\%) of managers answered that communication is good, while 10 (55.6\%) answered that it is bad. 


\section{Management of the revenue and expenditure of the care homes}

Regarding the data on the costs of the institution for salaries of employees, the data shows that in the period February, March and April in both public and private care homes there are no significant changes in the amount that the institution spends on salaries of employees. Also, for this period there are no significant changes in costs for water supply, electricity, telephone, internet, etc.

Data on the cost of procurement of food and food items shows that in March and April, compared to February, there were no significant changes in public care homes, while $50 \%$ of private care homes stated that they have higher costs. The increase in food costs ranges between $20 \%$ and $30 \%$, with 5 having an increase of $20 \%$ and 2 have $30 \%$.

When it comes to purchasing food products all 4 public and 14 private care homes stated that they do not have and have not had problems in the procurement of this type of products.

Regarding the costs of hygiene items, the data shows that all 4 public and 14 private care homes have an increase in the costs. The increase in this type of costs ranges from $20 \%$ to $30 \%$, while the average increase is $25 \%$.

Costs for procurement of medical protective equipment such as gloves, protective masks etc. shows an increase in both public and private care homes. Seventeen $(94.4 \%)$ of the care homes stated that they have an increase of this type of costs by $30 \%$ and one (5.6\%) elderly care home that have an increase of 50\%.

In terms of supply with personal protective equipment, the data show that all care homes that are part of the survey at the beginning of the crisis had serious problems in the procurement of medical protective equipment due to the lack of this type of products on the market and the dealers with which they cooperate.

In terms of revenue, the data shows that public care homes have a decrease in revenue due to the fact that in April they have a smaller number of residents compared to February. In private care homes data show that 13 (92.8\%) private care homes have no change in the amount of their income, while 1 (7.2\%) established an increase in revenue of $8 \%$ due to the fact they have risen the prices of their services.

Regarding the question whether the care home needs assistance from the government, 4 private care homes or $29 \%$ stated that they need financial assistance and assistance in protective equipment, while one elderly care home needs additional staff.

In terms of public care homes data shows that all four institutions need help from the state in the form of medical protective equipment and two institutions need additional staff. 
Regarding the economic measures provided by the Government of the Republic of North Macedonia for the private sector, the data shows that $4(28.6 \%)$ of the private care homes applied for financial assistance, but none of them received any assistance.

\section{Discussion}

Based on the obtained data, it is surprising the fact that even after more than two months after the first officially registered case of COVID-19 in the Republic of North Macedonia and the warnings of the WHO that the older adults are one of the most vulnerable categories of the population, the country has not yet created protocol for the work of the care homes for older adults during COVID-19 pandemic. As a result of this fact, the managers and the employees in the care homes on the basis of general guidelines have created their own mechanisms and set of protection activities that are adapted to the specifics and needs of the care homes, using information and guidance from relevant international sources.

However, despite this gap, the analysis shows that the elderly homes in the Republic of North Macedonia by the end of April 2020 successfully dealt with the pandemic and did not allow the virus to spread in the elderly care homes. Namely, in the surveyed 18 care homes with 947 residents, there are only two residents $(0.21 \%$ of the total number of care homes residents) who are infected with the virus and not a single deceased in whom the presence of the virus is registered. Regarding the situation with the care homes employees, out of a total of 401 employees, only 3 or $0.74 \%$ were tested positive for COVID-19. Which means that a total of five cases positive for COVID-19 have been registered, of which two are care homes residents and three are employees.

The five registered cases positive for COVID-19 in care homes (2 care homes residents and 3 employees) is $0.33 \%$ of the total registered cases in the country. This shows that the management and employees have taken appropriate measures and activities in order to protect against the spread of the virus in the care homes in the Republic of Northern Macedonia. Data from 21 high-income countries shows that while some countries have had no or very few deaths among residents in long-term care facilities, other countries report that on average nearly half of all deaths linked to COVID-19 in the country were of long-term care facility residents , ranging from $24 \%$ in Hungary to as high as $82 \%$ in Canada ( World Health Organization, 2020). 
In terms of revenue and expenditure management, it is characteristic that public care homes as a result of the fact that they are funded by the state, despite the reduced revenues and increased costs, still do not have financial problems. In contrast, private care homes that are financed only from the income they earn by selling their services, as a result of rising costs, face challenges in their regular operation. In order to deal with the financial challenges, some of the private care homes have applied for financial assistance from the state, but their applications have been rejected. In this context, it is important to emphasize that the state has not provided financial and other economic mechanisms for assistance and support to care homes. These institutions have at their disposal the general economic measures that are created for all economic operators, and according to the statements of the managers who are part of the research, these measures are not appropriate and do not meet the needs of the care homes.

Having in mind that at one time in the country a curfew was introduced with a ban and restriction of the movement of the population, there were also interruptions and/or changes in the organization of public transportation in the cities. For these reasons, the managers of the care homes had to introduce changes in the working hours of the employees and at the expense of the institution to organize transportation for their employees to and from the workplace.

As a result of the health recommendations for protection from COVID-19, the management, together with the employees in the care homes, have introduced some changes in the delivery of services. The group activities are avoided and individual activities are favored, but if certain group activities are implemented, they are organized in a small group and preferably in open space.

Also, all activities that previously took place in the community were replaced by individual activities or group online activities.

Based on the previously stated facts, it can be concluded that, till this moment, the managers of the care homes in the Republic of North Macedonia, successfully managed the institutions during COVID-19 pandemic and in that process mostly used their own knowledge, skills and the resources of its employees and institutions.

\section{Limitation of the Study}

The research provides important information, but it should be borne in mind that it also has some limitations. The main difficulty with the method of content analysis lies in how well the researchers succeeds in extracting meaningful categories from the data and in demonstrating how they tie in with that data (Hsieh and Shannon 2005).

One of the limiting factors is that, although data were obtained from $51.4 \%$ of the total number of the care homes in the Republic of North Macedonia, still the research does not cover all existing institutions. Also, the limiting factor is the fact that the survey was done online and there is no guarantee that the managers of the care homes have really completed the questionnaires. 


\section{Conclusion}

Based on the results it can be concluded that there are numerous challenges in the management of the care homes for older adults during COVID-19 pandemic. However, according to managers of care homes one of the main problems faced is the lack of official documents (protocols, guidelines, regulations with legal force, etc.) which regulate the operation of the elderly care homes during COVID-19 pandemic and which are adapted to the specifics and needs of these institutions. In this way, the managers of the care homes do not have clear, precise and specific directions, recommendations and instructions on how to act in their work. In order to fulfill this gap, to provide adequate protection against the virus, but also to ensure the efficient functioning of institutions in all aspects, managers in cooperation with their employees have mobilized all available resources and have created their own protection mechanisms that have proven to be effective until this moment.

However, in order to improve the level of prevention and dealing with the virus the state should create protocols for the operation of the care homes during COVID-19 pandemic. These protocols should give specific guidance on how managers and employees in care homes should act in three segments : 1) preventing the virus from entering the institution 2) preventing the spread of the virus in the institution 3) preventing the spread of virus outside the institution (if it has already entered the institution). It is very important protocols to be created by experts in the field of health, but with the active participation of representatives of care homes.

Also, it is very important public authorities (government, municipalities, state agencies etc.) to provide economic measures for care homes so that they can work effectively during COVID-19 pandemic.

\section{References}

[1] American Geriatrics Society, (2020). American Geriatrics Society (AGS) policy brief: COVID-19 and assisted living facilities. Journal of the American Geriatrics Society. May 2020: jgs.16510. doi: 10.1111 / jgs.16510;

[2] American Geriatrics Society, (2020). American Geriatrics Society policy brief: COVID-19 and nursing homes. Journal of the American Geriatrics Society. 2020; 68 (5): 908-11. doi: 10.1111 / jgs.16477;

[3] Arons MM, Hatfield KM, Reddy SC, Kimball A, James A, Jacobs JR et al. (2020). Presymptomatic SARS-CoV-2 infections and transmission in a skilled nursing facility. New England Journal of Medicine. 2020; 382: 2081-90. doi: 10.1056 / nejmoa2008457;

[4] British Geriatric Society (2020). Managing the COVID-19 pandemic in care homes for older people. Link: www.bgs.org.uk/COVID-19;

[5] Comas-Herrera A, (2020). Early evidence on preventing spread of COVID-19 in care homes: isolation of residents and staff who are symptomatic vs. suspected of COVID-19. Link: https://ltccovid.org/2020/04/01/early- 
evidence-on-preventing-spread-of-covid-19-in-care-homes-isolation-ofresidents-and-staff-who-are-symptomatic-vs-suspected-of-covid-19/;

[6] Comas-Herrera A, Zalakaín J, Litwin C, Hsu AT, Lane N, Fernández JL. (2020). Mortality associated with COVID-19 outbreaks in LTCFs: early international evidence. International Long-Term Care Policy Network. Link: https://ltccovid.org/2020/04/12/mortality-associated-with-covid-19outbreaks-in-care-homes-early-internationalevidence;

[7] Osterdahl M, Lee K, Ni Lochlainn M, Wilson S, Douthwaite S, Horsfall R et al. (2020). Detecting SARS-CoV-2 at point of care: preliminary data comparing loop-mediated isothermal amplification (LAMP) to PCR. SSRN Electronic Journal. 2020. doi: 10.2139 / ssrn.3564906;

[8] Gardner W, States D, MD, Bagley N (2020). The Coronavirus and the Risks to the Elderly in Long-Term Care, Journal of Aging \& Social Policy, Volume 32, 2020 - Issue 4-5: Older Adults and COVID-19: Implications for Aging Policy and Practice.

Link: https://www.tandfonline.com/doi/full/10.1080/08959420.2020.1750543

[9] Goldberg SA, Pu CT, Thompson RW, Mark E, Sequist TD, Grabowski DC. (2020). Asymptomatic spread of COVID-19 in 97 patients at a skilled nursing facility. Journal of the American Medical Directors Association. 2020.doi: 10.1016 / j.jamda.2020.05.040;

[10] Graham NSN, Junghans C, Downes R, Sendall C, Lai H, McKirdy A et al. (2020). SARS-CoV 2 infection: clinical features and outcome of COVID-19 in United Kingdom nursing homes. Journal of Infection. 2020; 5:38. doi: 10.1016 / j.jinf.2020.05.073;

[11] Guery R, Cécile D, Noëlle B, Nael V, Castain L, Raffi F et al. (2020). Limited effectiveness of systematic screening by nasopharyngeal RT-PCR of medicalized nursing home staff after a first case of COVID-19 in a resident. Medicine and Infectious Maldives. Link: doi: 10.1016 / j.medmal.2020.04.020;

[12] Institute for Public Health of the Republic of North Macedonia (2020).

[13] Links:a. https://www.iph.mk/sostojba-so-covid-vo-svetot-zaklucno-so-23-2020

[14] b. https://www.iph.mk/covid19-31-3-2020/

[15] c. https://www.iph.mk/covid-3042020/

[16] d. https://www.iph.mk/zdravo-i-aktivno-stareenje-za-vreme-na-covid19/

[17] Lee SH, Son H, Peck KR. (2020). Can post-exposure prophylaxis for COVID19 be considered as an outbreak response strategy in long-term care 
hospitals? International Journal of Antimicrobial Agents. April 2020; 105988. doi: 10.1016 / j.ijantimicag.2020.105988;

[18] Onder, G.; Rezza, G.; Brusaferro, S. (2020). Case-Fatality rate and characteristics of patients dying in relation to COVID-19 in Italy. JAMA 2020;

[19] Rita Petretto, D. and Pili, R. (2020). Ageing and COVID-19: What Is the Role for Elderly People? Geriatrics - Open Access Journal, Basel Switzerland;

[20] Shea YF, Lam HY, Yuen JKY, Cheng KCA, Chan TC, Mok WYW et al. (2020). Maintaining zero COVID-19 infection among long term care facility residents in Hong Kong. Journal of the American Medical Directors Association. May 2020. doi: 10.1016 / j.jamda.2020.05.042;

[21]World Health Organization, (2020). Infection Prevention and Control guidance for Long-Term Care Facilities in the context of COVID-19. https://apps.who.int/iris/bitstream/handle/10665/331508/WHO-2019nCoV-IPC_long_term_care-2020.1-eng.pdf;

[22] World Health Organization, (2020). Preventing and managing COVID-19 across long-term care services: Policy brief, 24 July 2020

[23] https://www.who.int/publications/i/item/WHO-2019-nCoV-Policy_BriefLong-term_Care-2020.1;

[24] World Health Organization, (2020). Coronavirus disease 2019 (COVID19), Situation Report - 40. https://www.who.int/docs/defaultsource/coronaviruse/situation-reports/20200229-sitrep-40-covid19.pdf?sfvrsn=849d0665_2;

[25] World Health Organization, (2020). Coronavirus disease 2019 (COVID19), Situation Report - 71. https://www.who.int/docs/defaultsource/coronaviruse/situation-reports/20200331-sitrep-71-covid19.pdf?sfvrsn=4360e92b_8;

[26] World Health Organization, (2020). Coronavirus disease 2019 (COVID19), Situation Report - 101. https://www.who.int/docs/defaultsource/coronaviruse/situation-reports/20200430-sitrep-101-covid19.pdf?sfvrsn=2ba4e093_2. 